\title{
Pemirolast Potassium
}

National Cancer Institute

\section{Source}

National Cancer Institute. Pemirolast Potassium. NCI Thesaurus. Code C47654.

The potassium salt form of pemirolast, a pyrimidinone derivative with antiallergic property. Pemirolast potassium exerts its action by blocking the antigen-mediated calcium ion influx into mast cells. This prevents mast cell degranulation, resulting in mast cell stabilization and inhibition of the release of inflammatory mediators, histamine and leukotrienes, which are involved in the allergic process. Pemirolast potassium also prevents inflammatory mediator release from eosinophils. 